\title{
Factors influencing duodenal trypsin levels following a standard test meal as a test of pancreatic function
}

\author{
I. J. ZEITLIN'1 AND W. SIRCUS
}

From the Wolfson Gastro-Intestinal Laboratories, Gastro-Intestinal Unit, Western General Hospital, Edinburgh.

SUMMARY In this investigation, the measurement of trypsin levels in duodenal juice following a standard test meal (Lundh test) was evaluated as a test of pancreatic function, and a study was made of diseases and other factors which may influence its diagnostic efficiency. The method of trypsin assay, which required only basic laboratory equipment, gave a linear concentration-activity curve, with a threshold at $50 \mu \mathrm{g}$ of crystalline trypsin per ml. Intestinal juice could be frozen and stored for up to six weeks with no detectable loss of tryptic activity.

The normal control values were very similar to those found by other workers and were unaffected by the sex or age of the subject. When used to assess 32 patients in whom the presence or absence of pancreatic disease had been clearly established, the test had a diagnostic success rate of $94 \%$.

Retrospective analysis of results from 98 patients showed that trypsin levels were generally grossly reduced in patients with chronic pancreatitis or carcinoma of the head of the pancreas. Trypsin levels were normal in most patients with steatorrhoea not of pancreatic origin. Levels were generally depressed to intermediate levels in patients with a diabetic glucose tolerance, with or without steatorrhoea, but no other sign of pancreatic insufficiency. Some lowering of trypsin levels was also noted in patients having an obstruction of the common bile duct. A small but significant depression of tryptic activity was noted in patients with villous atrophy and no pancreatic disease.

The measurement of the duodenal trypsin concentration following a standard meal as an index of exocrine pancreatic function was reported in a study of 12 patients by Lundh in 1962. This test was further developed and evaluated in a study on a larger scale by Cook, Lennard-Jones, Sherif, and Wiggins (1967). They reported that the test was of particular value in the diagnosis of pancreatic steatorrhoea. It was also of use in the diagnosis of chronic pancreatic disease and in the detection of pancreatic and ampullary carcinoma. A more recent study (McCarthy and Brown, 1969) compared the test with pancreatic scanning as a clinical pancreatic function test. These workers found that although the Lundh test will not detect tumours of the body or tail of the pancreas, otherwise the diagnostic power of the two tests is somewhat similar.

The present study further assesses the technique as a diagnostic test for pancreatic disease and ex-

${ }^{2}$ Present address: Department of Pharmacology, University of Strathclyde, Glasgow, G1 1 XW.

Received for publication 12 December, 1973. amines some of the additional factors which may influence its efficiency.

\section{Methods}

CLINICAL MATERIAL

The initial control series consisted of 17 patients, 13 males and four females, with final diagnoses including gastric ulcer, duodenal ulcer, and anxiety states. Their ages ranged from 19 to 63 years and they were without clinical, laboratory, or $x$-ray evidence of pancreatic disease, hepatobiliary disease, or malabsorption.

The clinical material consisted of 98 patients admitted to the Western General Hospital, Edinburgh, all thought to be possibly suffering from pancreatic disease. In order to judge the test as diagnostic of pancreatic disease, results were retrospectively evaluated for 32 patients for whom a diagnosis of diseased or healthy pancreas could be made with some certainty. For the purpose of this evaluation the diagnosis of normal was accorded only to those 15 patients in whom the negative laboratory and 
clinical findings had been supported by laparotomy. The group of 17 with pancreatic disease included only those in whom gross pancreatic abnormality had been established beyond doubt, generally through surgical intervention. This group included three with pancreatic carcinoma, six with chronic pancreatitis and calcification established surgically, four with obstruction of the pancreatic duct, and four with steatorrhoea plus a diabetic glucose tolerance curve.

Glucose tolerance curves were evaluated as described by the Committee of Statistics of the American Diabetes Society (Klimt, Prout, Bradley, Dolger, Fisher, Gastmean, Marks, Meinert, and Schumacher, 1969). Faecal fat excretion greater than $5 \mathrm{~g} / 24 \mathrm{hr}$ was diagnosed as steatorrhoea.

\section{CLINICAL METHODS}

The technique of pancreatic stimulation and sampling using a standard test meal was essentially that described by Cook et al (1967). The patients were studied after fasting overnight. A $12 \mathrm{Fr}$ gauge radioopaque tube with a mercury bag attached was passed through the mouth. The tip was adjusted so that it was in the region of the duodenal jejunal flexure, or, in patients with a Polya partial gastrectomy, about $8 \mathrm{~cm}$ past the stoma. The position of the tube was checked at the start and finish of the test. The duodenal juice was aspirated under gentle suction and collected in a flask on ice. The resting juice was aspirated and discarded. A standardized meal was then given containing $18 \mathrm{~g}$ corn oil, $15 \mathrm{~g}$ dried milk protein, $4 \mathrm{~g}$ glucose, flavoured with $15 \mathrm{~g}$ fruit syrup and made up to $300 \mathrm{ml}$ with warm water. It was found useful to use a strongly coloured fruit syrup, as this gave an immediate indication of contamination of the aspirate by the test meal. The resultant meal contained $6 \%$ fat, $5 \%$ protein, and $15 \%$ carbohydrate. The duodenal juice was then collected for four consecutive half-hour periods. The appearance, colour, and $\mathrm{pH}$ of each aspirate was recorded and an aliquot was rapidly frozen and stored at $-20^{\circ} \mathrm{C}$ until enzyme assay. Specimens were stored for up to four weeks.

\section{BIOCHEMICAL METHODS}

For this study the method of trypsin assay was that of Wiggins (1967) requiring only a stop-clock and $\mathrm{pH}$ meter. The substrate solution contained $0.5 \%$ $\mathrm{N}$-benzoyl-L-arginine ethyl ester (BAEE) in 0.1 barbitone sodium adjusted to $\mathrm{pH} 9$ with sodium hydroxide. Intestinal juice was diluted $1: 10$ or $1: 5$ with $0.05 \mathrm{M}$-acetate buffer at $\mathrm{pH} 5.8$ containing $0.5 \mathrm{~g}$ calcium chloride per litre. One millilitre of the diluted juice was added to $5 \mathrm{ml}$ of the BAEE solution in a reaction vial maintained at $25^{\circ} \mathrm{C}$ on a magnetic stirrer. The $\mathrm{pH}$ electrode was immersed in the reac- tion mixture, the $\mathrm{pH}$ was allowed to fall to exactly $\mathrm{pH} 8$, and $0.1 \mathrm{ml}$ of $0.04 \mathrm{~N}-\mathrm{NaOH}$ was added immediately. The time taken for the $\mathrm{pH}$ to return to 8 was measured. The measured period is the time taken for the release of $4 \mu$-equiv of $\mathrm{H}^{+}$. A 1:5 diluted intestinal juice taking more than 10 minutes was recorded as less than $2 \mu$-equiv $/ \mathrm{min} / \mathrm{ml}$. Hydrogen ion released as microequivalents per minute per $\mathrm{ml}$ of intestinal juice was calculated as ( $\mu$-equiv $\mathrm{NaOH}$ added) $\times$ (dilution of juice)/(time) .

\section{STATISTICS}

Values in the control group were found to be normally distributed. The statistical significance of differences was evaluated using Student's t test. Abnormally reduced trypsin secretion was defined as more than 2 sd below the mean normal value.

\section{Results}

\section{METHODOLOGY}

\section{Linearity of trypsin assay}

Assay of varying dilutions of crystalline trypsin (Tryptar, Armour) in $0.001 \mathrm{M} \mathrm{HCl}$ gave a linear concentration activity curve (fig 1 ). The threshold of the routine assay, when carried out as described, was equivalent to $50 \mu \mathrm{g}$ of the trypsin preparation per $\mathrm{ml}$.

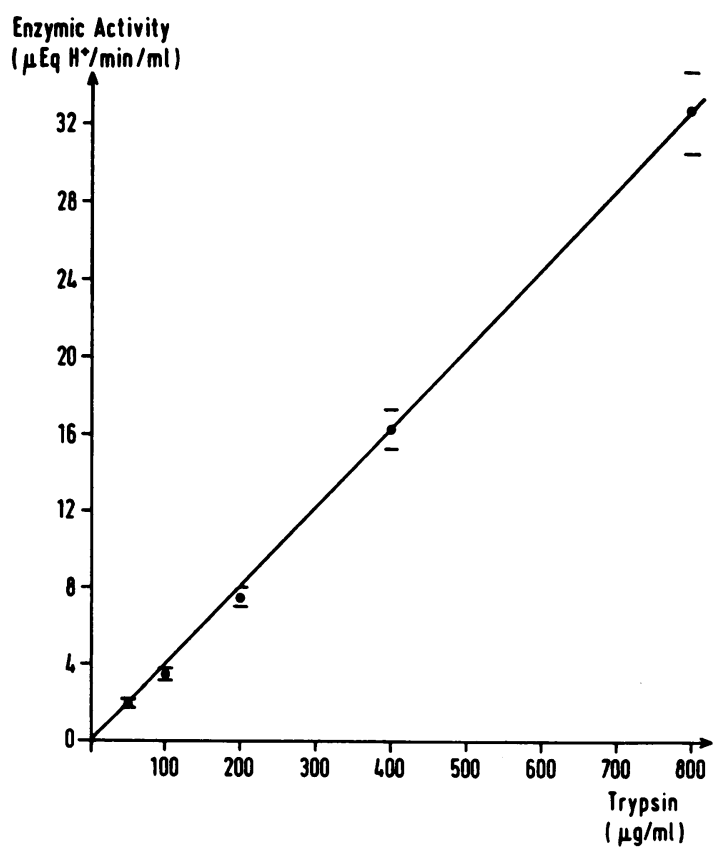

Fig 1 Assay of the BAEE esterase activity of varying dilutions of crystalline trypsin showing linear concentration activity curve. 
Results in the clinical study are quoted as the rate of $\mathrm{H}^{+}$release produced by the trypsin content of $1 \mathrm{ml}$ of intestinal juice, since this permits the statement of results in international units ( $\mathrm{U}$ equiv $\mathrm{H}^{+}$/ $\mathrm{min} / \mathrm{ml}$ ) which do not depend on the origin of a particular standard trypsin preparation.

\section{Effect on samples of freezing and storage}

Choi, Goldstein, Wirts, and Menduke (1976) have reported that freezing samples of intestinal juice before assay produced losses of tryptic activity of over $50 \%$, while storage at $4^{\circ} \mathrm{C}$ for up to seven days produced only small losses of up to $15 \%$.

To test the effect of freezing, a sample of intestinal juice was obtained from eight subjects. An aliquot was taken from each sample and its tryptic activity was measured immediately following aspiration. A second aliquot was frozen, stored for six weeks at $-20^{\circ} \mathrm{C}$, thawed, and re-assayed. Table I shows that there was no detectable change activity after storage ( $P>0.05)$.

It was found that certain precautions were necessary to prevent losses of tryptic activity on storage. Aspirates were collected on ice and immediately frozen. Thawing was carried out rapidly, ie, not at room temperature, using a water bath at between 37 and $40^{\circ} \mathrm{C}$. Slow thawing or thawing above $40^{\circ} \mathrm{C}$ produced detectable losses.

\begin{tabular}{lll}
\hline Sample & $\begin{array}{l}\text { Fresh Juice } \\
\left(\mu \text {-equiv } H^{+} / \min / \mathrm{ml}\right)\end{array}$ & $\begin{array}{l}\text { Frozen Juice } \\
\left(\mu \text {-equiv } \mathrm{H}^{+} / \mathrm{min} / \mathrm{ml}\right)\end{array}$ \\
\hline 1 & 21.6 & 22.0 \\
2 & 17.9 & 16.8 \\
3 & 11.3 & 11.5 \\
4 & 16.1 & 15.7 \\
5 & 20.7 & 21.6 \\
6 & 30.6 & 32.9 \\
7 & 29.1 & 31.8 \\
8 & 29.3 & 29.3 \\
Mean & 22.1 & 22.7 \\
No significant difference between means $0.45>\mathrm{P}>0.40$ \\
\hline
\end{tabular}

Table I Effect of freezing and thawing on tryptic activity in duodenal juice
Control values

Trypsin secretion in a control group of 17 'paranormal' patients (see Methods: Clinical Material) was measured in duodenal juice following ingestion of the standard test meal as already described. Both the peak 30-minute tryptic activity and the mean value during the two-hour period were determined. The results are shown in table II compared with the control values found by Cook et al (1967). Table II shows the P values (Student's $t$ ) for the comparison between the two sets of means, assuming that they are assessments of the same normal values.

It can be seen that there is very close agreement between the peak and mean two-hour tryptic activities in the two series and the differences are not statistically significant. There is a very marked difference between the volume of aspirate in the two series $(P<0.01)$ possibly reflecting the different methods of collection. However, in both series the very large coefficients of variation make volume an unsuitable diagnostic parameter.

Cook et al (1967) found that the mean two-hour activity had the lowest coefficient of variation (table II) and used this as their routine diagnostic parameter. In the present series, the peak 30-minute tryptic activity had a lower coefficient of variation $(25.2 \%)$ when compared with the mean two-hour value and this is used as the diagnostic parameter in all subsequent studies. For diagnostic purposes, the lower limit of normal is defined as mean $-2 \times$ standard deviation (see table II).

\section{Effect of sex and age on tryptic activity}

The control series for this study contained only four female out of 17 subjects; the sex ratio of the control group of Cook et al (1967) is not disclosed. It is thus necessary to determine whether duodenal tryptic activity is related to the sex of the patient. Subsequently, when the clinical series contained sufficient female patients with no known pancreatic involvement, duodenal trypsin activities from the first 10 male and female patients having no detectable pan-

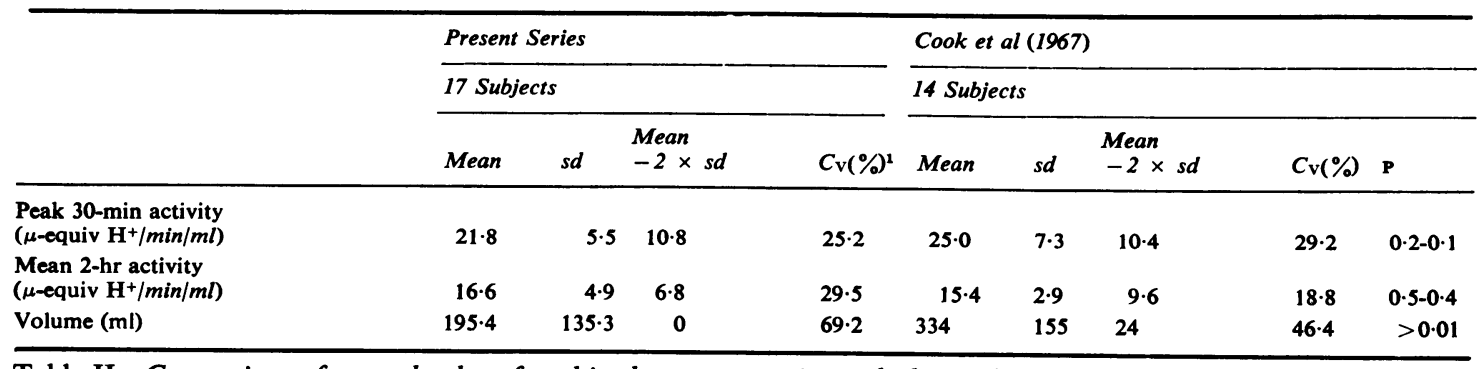

Table II Comparison of normal values found in the present series with those of Cook et al (1967)

${ }^{1}$ The coefficient of variation $(\mathrm{Cv} \%)$ is defied as $\frac{\text { Standard deviaton }}{\text { Mean }} \times 100$ 


\begin{tabular}{|c|c|c|c|c|}
\hline \multicolumn{3}{|c|}{ Peak 30-min Tryptic Activity ( $\mu$-equiv $\mathrm{H}^{+} / \mathrm{min} / \mathrm{ml}$ ) } & \multicolumn{2}{|c|}{ Average 2-hr Tryptic Activity $\left(\mu\right.$-equiv $\left.\mathrm{H}^{+} / \mathrm{min} / \mathrm{ml}\right)$} \\
\hline & Male Group & Female Group & Male Group & Female Group \\
\hline & $\begin{array}{l}19.8 \\
18.0 \\
14.2 \\
25.3 \\
14.3 \\
24.1 \\
20.3 \\
21.6 \\
30.6 \\
25.0\end{array}$ & $\begin{array}{l}15.6 \\
18.6 \\
33.1 \\
22.0 \\
27.9 \\
30.0 \\
20.0 \\
20.0 \\
19.5 \\
19.8\end{array}$ & $\begin{array}{l}14.8 \\
11.3 \\
13.5 \\
15.1 \\
13.9 \\
22.2 \\
16.2 \\
16.5 \\
26.7 \\
15.6\end{array}$ & $\begin{array}{l}12.2 \\
10.5 \\
23.7 \\
17.7 \\
34.6 \\
17.9 \\
13.7 \\
15.3 \\
10.3 \\
10.4\end{array}$ \\
\hline \multirow[t]{2}{*}{$\begin{array}{l}\text { Mean } \\
\text { sd }\end{array}$} & $\begin{array}{r}21 \cdot 3 \\
5 \cdot 1\end{array}$ & $\begin{array}{r}22 \cdot 7 \\
5.7\end{array}$ & $\begin{array}{r}16 \cdot 6 \\
4 \cdot 5\end{array}$ & $\begin{array}{r}16 \cdot 6 \\
7.6\end{array}$ \\
\hline & \multicolumn{2}{|c|}{$\begin{array}{l}\text { No significant difference } \\
P>0.35 \text { (Student's } t \text { ) }\end{array}$} & \multicolumn{2}{|c|}{$\begin{array}{l}\text { No significant difference } \\
P>0.45\end{array}$} \\
\hline
\end{tabular}

Table III Analysis of sexual differences in trypsin response of control subjects to standard meal

creatic disease were compared (table III). Neither the peak 30-minute activity nor the mean two-hour activity showed any significant difference between the two groups.

Similarly there was no correlation between age and peak 30-minute trypsin activity in a group of 21 males aged 19-68 having no known pancreatic disease $(\mathrm{r}=0.03)$.

\section{CLINICAL STUDIES}

\section{Diagnostic reliability}

To evaluate the measurement of duodenal tryptic activity following a test meal as a diagnostic test of pancreatic malfunction, peak 30-minute trypsin activities were compared in a group of 32 patients. Of these, 15 patients were subsequently found to have no discernible pancreatic disease, this group including only those in whom negative laboratory and clinical findings were supported by laparotomy. The remaining group of 17 patients includes only those in whom there is clear evidence of gross pancreatic disease (see Clinical Material).

The peak 30-minute trypsin values for these patients are shown in figure 2 . It can be seen that only two out of 32 of the trypsin results differ from the diagnoses, one normal and one abnormal, giving a success rate of $94 \%$.

\section{Influence of various clinical conditions on trypsin secretion}

In order to gain a more detailed analysis of the clinical conditions associated with depression of the peak trypsin value the case histories were studied of the 30 patients in the total series of 98 having a peak trypsin activity 2 standard deviations or more below the normal mean. These patients fall into the following categories: chronic or recurrent pancreatitis (7) established at laparotomy or by the presence of pancreatic calcification, carcinoma of the head of the pancreas (3), diabetes or diabetic glucose tolerance test plus steatorrhoea with no other indication of pancreatic disease (5), diabetes or diabetic GTT alone (5), villous atrophy with or without non-pancreatic steatorrhoea (3), obstruction of the common bile duct (4), steatorrhoea alone of non-pancreatic origin (1). Only two patients did not fit clearly into one of these categories.

Case histories of the total series of 98 patients were then reviewed, and the peak trypsin values of all patients fitting one of the above categories were extracted, regardless of whether they were normal or

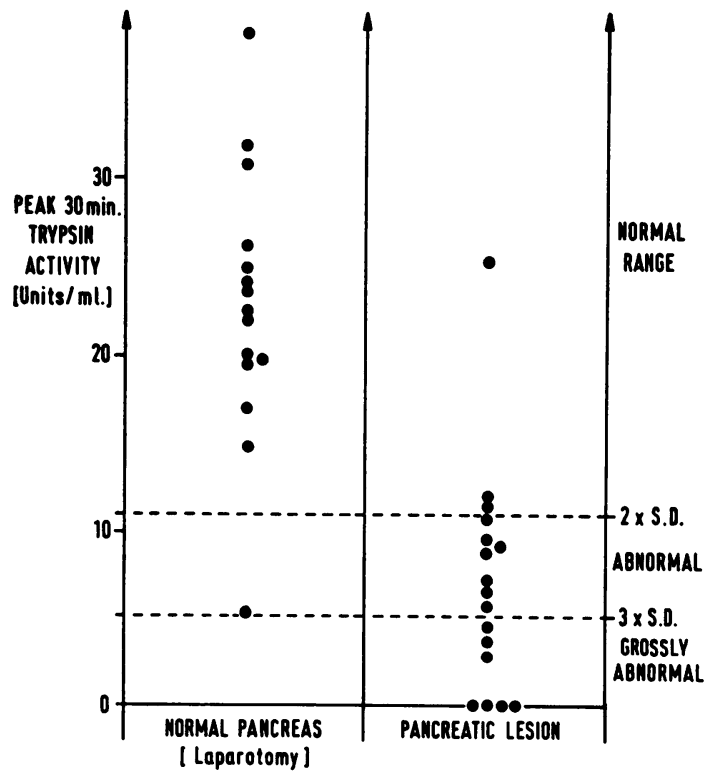

Fig 2 Comparison of tryptic activity in peak 30-minute collections in 32 patients with normal or diseased pancreas. 


\begin{tabular}{|c|c|c|c|c|c|c|c|}
\hline $\begin{array}{l}\text { Number of } \\
\text { Patients }\end{array}$ & $\begin{array}{l}\text { Pancreotic } \\
\text { Carcinoma } \\
\text { (head) }\end{array}$ & $\begin{array}{l}\text { Chronic or } \\
\text { Recurrent } \\
\text { Pancreatitis }\end{array}$ & $\begin{array}{l}\text { Diabetic GTT } \\
+ \text { Steator- } \\
\text { rhoea }\end{array}$ & $\begin{array}{l}\text { Diabetic GTT } \\
\text { Alone }\end{array}$ & $\begin{array}{l}\text { Villous } \\
\text { Atrophy }\end{array}$ & $\begin{array}{l}\text { Obstruction of } \\
\text { Common bile } \\
\text { Duct }\end{array}$ & $\begin{array}{l}\text { Steatorrhoea } \\
\text { Alone (Non- } \\
\text { pancreatic) }\end{array}$ \\
\hline Total in study & 3 & 8 & 5 & 7 & 6 & 7 & 6 \\
\hline 2 sd-3 sd below normal mean & $\mathbf{0}$ & 1 & 5 & 2 & 2 & 4 & 1 \\
\hline 3 sd below normal mean & 3 & 6 & $\mathbf{0}$ & 3 & 1 & $\mathbf{0}$ & $\mathbf{0}$ \\
\hline Total abnormally low & 3 & 7 & 5 & $\mathbf{5}$ & 3 & 4 & 1 \\
\hline Mean & $3 \cdot 3$ & $\mathbf{3 \cdot 3}$ & $9 \cdot 2$ & $9 \cdot 4$ & 10.6 & $12 \cdot 6$ & $15 \cdot 0$ \\
\hline sd ( $\mu$-equiv $\left.\mathbf{H}^{+} / \mathrm{min} / \mathrm{ml}\right)$ & 2.9 & $4 \cdot 1$ & 1.4 & $10 \cdot 4$ & $5 \cdot 0$ & $7 \cdot 2$ & $4 \cdot 1$ \\
\hline
\end{tabular}

Table IV Numbers of patients in each category and the number having a peak 30-minute trypsin level 2 or 3 sd (10.8 and $5 \cdot 3 \mu$-equiv $\mathrm{H}^{+} / \mathrm{min} / \mathrm{ml}$ respectively) below the normal range

abnormal. The results are shown in table IV. It can be seen that seven out of the eight patients investigated with confirmed chronic or recurrent pancreatitis had peak trypsin values more than 2 sd below the normal mean, while six of these fell more than 3 sd below the normal mean. The one normal value at $11.5 \mu$-equiv $/ \mathrm{min} / \mathrm{ml}$ lay near the borderline. Likewise all three of the patients with carcinoma of the head of the pancreas had peak trypsin values more than 3 sd below the mean normal value.

Of the patients with diabetes or a diabetic glucose tolerance curve in the presence of steatorrhoea with no other indication of pancreatic involvement, five out of five had a peak trypsin value more than 2 sd below the normal mean value, although none fell below 3 sd. The mean peak trypsin concentration for this group, 9.2 $\mu$-equiv $\mathrm{H}^{+} / \mathrm{min} / \mathrm{ml}(\mathrm{sd}=1.4)$, was significantly less than the mean normal value $(\mathrm{P}<0.001)$. Patients with diabetes or diabetic glucose tolerance with no detected impairment of pancreatic exocrine function also had a mean value just outside the normal range, $9.4 \mu$-equiv $\mathrm{H}^{+} / \mathrm{min} / \mathrm{ml}$ but had a much greater scatter (fig 3). In this group five out of seven results fell below the normal range.

The defining of the group of six with partial or total villous atrophy, with or without steatorrhoea, was unexpected and came to light as the result of assigning all of the other abnormal values to their various categories. Out of a total of six patients with villous atrophy, three had a peak trypsin concentration below the normal range, the remaining three fell at the lower end or normal. The resulting mean value of $10.6 \mu$-equiv $\mathrm{H}^{+} / \mathrm{min} / \mathrm{ml}(\mathrm{sd}=5.0)$ is just outside the normal range, and proved to be significantly lower than the normal mean $(P<0.001)$.

Of the group of seven patients with obstruction of the common bile duct, four fell between 2 and 3 standard deviations from normal while one was a borderline case. The mean peak trypsin value for this group, $12.6 \mu$-equiv $\mathrm{H}^{+} / \mathrm{min} / \mathrm{ml}$, is significantly lower than that of the normal group $(P<0.01)$.

The final group of six patients presenting with steatorrhoea of non-pancreatic origin contained only one value outside the normal range. The mean value for this group of $15.0 \mu$-equiv $\mathrm{H}^{+} / \mathrm{min} / \mathrm{ml}$ was not significantly lower than normal $(P>0.05)$.

Figure 3 shows a comparison of the peak 30minute trypsin values from 42 patients classified into the seven disease groups.

\section{Discussion}

The method of assessment of pancreatic exocrine function used in the present study is probably the simplest and least unpleasant for the patient of those in current use. After an overnight fast, a single lumen tube is passed into the duodenum. A test meal containing standard amounts of protein, carbohydrate, and fat provides a physiological stimulus of pancreatic activity (Lundh, 1962; Cook et al, 1967). Following the stimulus, duodenal juice is sampled

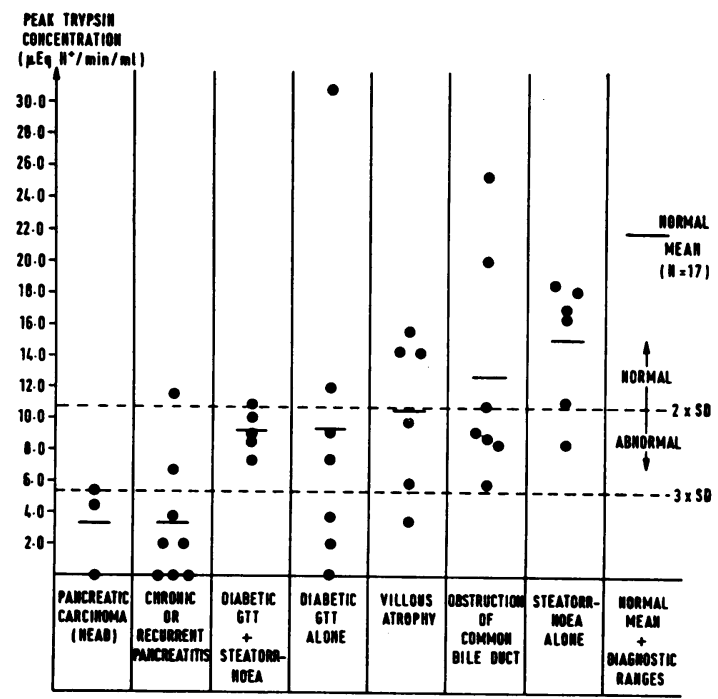

Fig 3 Comparison of peak 30-minute tryptic activities in 42 patients classified into seven disease groups. Horizontal dashes represent mean values for each group. 
for a period of two hours at 30-minute intervals and its trypsin content measured. The peak 30-minute trypsin concentration (Cook et al, 1967) or the mean trypsin concentration over the two-hour period (Lundh, 1962; Cook et al, 1967) may be used as a measure of pancreatic function. The method used in the present study for the estimation of trypsin was that of Wiggins (1967) requiring only basic laboratory equipment. It is thus suitable for laboratories where the relatively expensive autotitrator or spectrophotometer required by other more sophisticated methods of trypsin estimation are not available.

Despite its simplicity, the assay was found to give good linearity as long as precautions relevant to any method of trypsin assay were taken. Comparison of the normal values for duodenal trypsin concentration found in this study with those of Cook et al (1967), who also used the assay method of Wiggins, shows that this pancreatic function test gives a high degree of reproducibility between laboratories. Cook et al (1967) used the mean two-hour tryptic activity as their diagnostic parameter. In the present study, we found that the peak 30-minute activity had a smaller coefficient of variation and we therefore used the peak value as the diagnostic parameter. The normal value for this parameter was found to be unrelated either to the sex or age of the patient.

The test was applied to a group of 32 patients in whom the presence or absence of gross pancreatic disease was subsequently established beyond reasonable doubt by clinical and laboratory findings and laparotomy. Using 2 standard deviations below the mean as the lower limit of normal the test gave a very high diagnostic success rate $(94 \%)$. Only one out of 15 normal patients and one out of 17 abnormal patients were incorrectly diagnosed.

Following the initial evaluation, the test went into routine diagnostic use and at the time of making this survey results were available from a total of 98 patients. Analysis of the results showed that chronic or recurrent pancreatitis and carcinoma of the head of the pancreas were associated with extremely depressed peak trypsin levels (more than 3 sd below the normal mean in six out of eight and three out of three patients respectively). These findings support the original conclusions of Lundh (1962) and of subsequent workers (Cook et al, 1967; McCarthy and Brown, 1969).

The conclusions of Cook et al (1967) were likewise supported by the finding that peak trypsin values were not significantly lower than normal in patients with steatorrhoea of non-pancreatic origin, five out of six values lying within the normal range. The study revealed a further category of patient presenting with steatorrhoea who, in addition, dis- played a diabetic glucose tolerance curve but showed no other signs of pancreatic disease. All five of the patients in this category had abnormally low peak trypsin levels: the mean value for this group, $\mathbf{9 \cdot 2}$ $\mu$-equiv $\mathrm{H}^{+} / \mathrm{min} / \mathrm{ml}(\mathrm{sd}=1.4)$, was significantly less than normal $(\mathrm{P}<0.001)$. Of a further group of seven patients with diabetes or diabetic glucose tolerance but no steatorrhoea or any other sign of pancreatic exocrine insufficiency, five also had abnormally low peak trypsin levels.

Reduced trypsin in response to a test meal in uncomplicated diabetics has not previously been reported. Indeed McCarthy and Brown (1969) found no correlation between the results of the Lundh test and those of the glucose tolerance test. There is a considerable body of evidence to indicate the presence of pancreatic exocrine insufficiency in from 30 to more than $70 \%$ of diabetics (Jones, Castle, Mulholland, and Bailey, 1925; Pollard, Millar, and Brewer, 1943; Dreiling, 1951; Chey, Shay, and Shuman, 1963; Vacca, Henke, and Knight, 1964; Bock, Bank, Marks, and Jackson, 1967). Furthermore, when uptake of ${ }^{75} \mathrm{Se}$-methionine is used as a test of pancreatic exocrine function, a number of authors have reported reduced pancreatic uptake in diabetics with no other indication of pancreatic disease (Sodee, 1966; Lädhevirta, 1967; Melmed, Agnew, and Bouchier, 1968; McCarthy and Brown, 1969). In patients with uncomplicated diabetes mellitus, the depression of trypsin secretion following the test meal would appear to be a further indication that reduced pancreatic exocrine activity may accompany that disease. It is clear that in such patients the results of any of the pancreatic function tests in current use must be interpreted with great care.

Of the seven patients in the series having obstruction of the common bile duct (six with gallstones and one with fibrotic stricture of the duct), four had abnormally low peak trypsin values, a fifth was a borderline case. The mean value for the group was significantly less than the normal value $(P<0.01)$. Cook et al (1967) reported that of the three patients in their series with a gallstone at the lower end of the common bile duct, two gave a low result.

The group of patients having in common varying degrees of villous atrophy was noticed after all of the more obvious apparent sources of reduced trypsin activity had been eliminated. Out of six of these patients, three of whom presented with steatorrhoea, three had abnormally low trypsin levels, although there was no relationship between trypsin level and the presence or absence of steatorrhoea. The mean value for the group was significantly less than the normal value ( $\mathrm{P}<0.001)$. Although Cook et al (1967) had not noted a similar finding, when we analysed their results we saw that of 10 patients presenting 
with non-pancreatic causes of steatorrhoea, five had varying degrees of villous atrophy. The mean peak trypsin value of the group with no villous atrophy $\left(19.4 \pm 7 \cdot 5 \mu\right.$-equiv $\left.\mathrm{H}^{+} / \mathrm{min} / \mathrm{ml}\right)$ was not significantly less than the mean normal value $(25 \pm 7 \cdot 3 \mu$-equiv $\mathrm{H}^{+} / \mathrm{min} / \mathrm{ml}$ ) with $\mathbf{P}>0.05$, while the mean peak trypsin value in the group with villous atrophy $(16.7 \pm 5.5)$ was significantly less than the normal value $(P<0.025)$. Trypsin is secreted by the pancreas as the inactive precursor, trypsinogen. It is activated in the lumen of the small intestine by the enzyme enterokinase which is released from the brushborder membrane of the small intestinal epithelial cell (Nordström and Dahlquist, 1970; Hadorn, Steiner, Sumida and Peters, 1971). It seems reasonable to expect that conditions producing destruction of the intestinal mucosa should also influence the intraluminal concentration of active trypsin.

The Lundh test of pancreatic function requires no potentially dangerous intravenous injection of hormones or radioactive compounds with the possibility of undesirable side effects. The assessment can be obtained by measuring a single parameter using a very simple assay technique. The test will consistently indicate the presence of chronic pancreatitis and pancreatic carcinoma and distinguish nonpancreatic steatorrhoea from steatorrhoea of pancreatic origin. False-positive results may be obtained in the presence of diabetes mellitus, bile duct obstruction, and villous atrophy.

We are grateful to Mr D. R. Keys for technical assistance with the trypsin assay. We thank the physicians and surgeons of the Western General Hospital for their interest and cooperation. This research was supported by a Medical Research Council temporary grant to Dr W. Sircus.
References

Bock O. A. A., Bank, S., Marks, I. N., and Jackson, W. P. U. (1967). Exocrine pancreatic function in diabetes mellitus. S. Afr. med. J., 41, 756-758.

Chey, W. Y., Shay, H., and Shuman, C. R. (1963). External pancreatic secretion in diabetes mellitus. Ann. intern. Med., 59, 812-821.

Choi, H. J., Goldstein, F., Wirts, C. W., and Menduke, H. (1967). Normal duodenal trypsin values in response to secretin-pancreozymin stimulation with preliminary data in patients with pancreatic disease. Gastroenterology, 53, 397-402.

Cook, H. B., Lennard-Jones, J. E., Sherif, S. M., and Wiggins, H. S. (1967). Measurement of tryptic activity in intestinal juice as a diagnostic test of pancreatic disease. Gut, 8, 408-414.

Dreiling, D. A. (1951). Studies in pancreatic function. IV. The use of the secretin test in the diagnosis of tumors in and about the pancreas. Gastroenterology, 18, 184-196.

Hadorn, B., Steiner, N., Sumida, C., and Peters, T. J. (1971). Intestinal enterokinase. Mechanisms of its 'secretion' into the lumen of the small intestine. Lancet, 1, 165-166.

Jones, C. M., Castle, W. B., Mullholland, H., and Bailey, F. (1925). Pancreatic and hepatic activity in diabetes mellitus. Arch. intern. Med., 35, 315-336.

Klimt, C. R., Prout, T. E., Bradley, R. F., Dolger, H., Fisher, G., Gastineau, C. F., Marks, H., Meinert, C. L., and Schumacher, O. P. (1969). Standardization of the oral glucose tolerance test. Diabetes, 18, 299-310.

Lähdevirta, J. (1967). Testing of exocrine function of pancreas in diabetes mellitus by use of ${ }^{75} \mathrm{Se}$-methionine and of secretin. Acta med. scand., 182, 345-351.

Lundh, G. (1962). Pancreatic exocrine function in neoplastic and inflammatory disease; a simple and reliable new test. Gastroenterology, 42, 275-280.

McCarthy, D. M., and Brown, P. (1969). Measurement of duodenal tryptic activity and ${ }^{75} \mathrm{Se}$-selenomethionine pancreatic scanning compared as tests of pancreatic function. Gut, 10, 913-920.

Melmed, R. N., Agnew, J. E., and Bouchier, I. A. D. (1968). The normal and abnormal pancreatic scan. Quart. J. Med., 37, 607-624.

Nordström, C., and Dahlquist, A. (1970). The cellular localization of enterokinase. Biochim. biophys. Acta. (Amst.)., 198, 621-622.

Pollard, H. M., Miller, L., and Brewer, W. A. (1943). The external secretion of the pancreas and diabetes mellitus. Amer. J. dig. Dis., 10, 20-23.

Sodee, D. B. (1966). Pancreatic scanning. Radiology, 87, 641-645.

Vacca, J. B., Henke, W. J., and Knight, W. A., Jr. (1964). The exocrine pancreas in diabetes mellitus. Ann. intern. Med., 61, 242-247.

Wiggins, H. S. (1967). Simple method for estimating trypsin. Gut, 8, 415-4i6. 